\title{
The Interpretation of Communication Disorders in $A$ Temporary Matter
}

\author{
QIAN Zi-ying \\ School of Business, Hohai University \\ Nanjing 211100, China
}

\begin{abstract}
The aim of this article is to analyze universal social issue-communication disorders in the maiden work of Jhumpa Lahiri, which is encountered when characters in the novel named Shukumar and Shoba immigrated to America. This paper applies descriptive methods, case study method and literature analysis method to reveal the recurring themes of barriers and opportunities for human communication and community. After the analysis of the predicament of family communications, this paper discusses the causes of communication barriers faced by main characters in four aspects, including different cultural backgrounds, life pressure, the different views of marriage and love and serious accidents. Finally, mainly based on the theory of management communication, this paper puts forward two corresponding solutions to solve communication barriers from the perspectives of face-to-face conversations and listening to each other.
\end{abstract}

Keywords-Communication disorders; Family relationship; A Temporary Matter; Jhumpa Lahiri

\section{INTRODUCTION}

Interpreter of Maladies is the first work of Jhumpa Lahiri, who is a gifted female writer in Asian-American literature. This maiden work wins the Pulitzer Prize for fiction as well. This collection consists of nine stories, one of which is A Temporary Matter. This novel tells a story that a young couple, Shukumar and Shoba, who are reeling from the loss of their child, try their best to avoid each other and eventually break their family relationship. The importance of communication within a marriage is a prevalent theme in Interpreter of Maladies, and A Temporary Matter as well. A Temporary Matter is a story about grief and the secrets people keep from one another. Husband and wife, named Shukumar and Shoba, are reeling from the loss of their child six months earlier. After that heart-breaking accident, they keep avoiding each other and their friends, Shoba starts to fill her time with work and Shukumar procrastinats in finishing his thesis. Gradually, they learn not to mind the silence and even become strangers to each other. A deus-ex-machine in the form of systematic power outages finally allows for intimacy and communication between the couple not achieved since the death of their son. Their time in the dark turned into an exchange of confessions about how they had hurt or disappointed each other or themselves.
After the research and analysis of this novel, this thesis applies descriptive methods, case study method and literature analysis method to reveal the recurring themes of the barriers to and opportunities for human communication and community. This thesis begins with the introduction of the background information of Lahiri, her debut novel discussed in this thesis and previous studies on family communications. Then, the predicament of family communication obstacles are pointed out in Chapter two. The main body followed of this thesis containing four parts to analysis the comprehensive causes which give rise to communication disorders. At last, corresponding solutions are proposed.

\section{CHAPTER ONE LITERATURE REVIEW}

\section{A. Previous Studies on A Temporary Matter}

Jhumpa Lahiri, born in 1967, is one of those gifted contemporary female novelists in the United States. Lahiri has created several works talking about immigrant experiences, generation gaps and identity issues. She has an unique growing environment which grants her a keen understanding of the tragedy of human, and makes her novel extraordinary. Seemingly recurrent on the theme, her works actually differ in focus. As a contemporary writer, her works are relatively new, so the research and comments on Lahiri are not so abundant. In fact, most of the existed researchers put emphasis on her first work: Interpreter of Maladies, which helps her win the Pulitzer Prize.

Broadly speaking, the novel has been praised by many American researchers who emphasize the theme, narrative strategy or the exploration of the characters' living predicaments and writing skills. Among those critics who concentrate on the identity problem, Judith Caesar initiates his argument on the interaction between people and the self [2]. He considers that character's anxiety about identity issue is not only relevant to bi-cultural atmosphere, but the lack of selfunderstanding to see oneself as an alternative and binary self.

Moreover, the relevant studies of Lahiri and her works in China mainly analyze it from the views of the theme, the diasporic literature study or cultural explanation and as forth as follows. Lv Qingze's thesis attempts to expound Interpreter of Maladies and A Temporary Matter on the theme of malady in society. He puts forward that communication disorders make the character harder to survive in different cultural environment. 
Huang Xin develops his thesis mainly on trauma and secondgeneration immigrants who faced up with cultural conflicts.

There are also other research directions different from what I mentioned above, which makes the scope of research lager on A Temporary Matter. Xie Yulu concentrates on female characters in her article by analyzing Interpreter of Maladies, The Lost, God of Small Things, and The Namesake with the ideology of Feminism [9]. For the author, woman's racial identity could be achieved by melting into the new culture and paying little attention to the homeland culture.

Many of Lahiri's works talk about people's physical and psychological maladies. It is difficult to summarize her meticulous attention to character detail and deft management of secrets among lovers, husbands and wife [8]. The universality of cultural problems can be perceived on immigrants with the development of globalization as well. The cultural diversity of those ethnic groups is kept as well. Because of the featured significance of cultural problems, the immigrant literature is increasingly created and valued. The studies on Lahiri's works are not abundant in the literature world right now, especially the studies in China are even less. Comparatively fewer articles touch upon the analysis of communication disorders in Lahiri's novels. So the profound researches and more discussions in China are badly in need.

\section{B. Previous Studies on Family Communications}

The research on family communication pattern theory has spanned two generations and has a long history of forty years [6]. It was firstly conceptualized by Jack M. Mcleod and Steven. R[10]. Chaffee. These scholars proposed the coorientation cognitive theory to explain the process of family communication [6]. However, they did this research in the media field and assumed that the communication pattern is from "experience in interaction rather than personality characteristics" [3].

Then Ritche and Fitzpatrickhas developed the research in the family communication field with the assumption that family communication pattern is rooted in the family value and belief [6]. They put forward that family environment should emphasize the consistency of value, as well as attitude of family members, while the conversation orientation refers to the family environment which is related to the open communication and independent opinions of family members [5]. Ritche and Fitzpatrick's theory has developed McLeod and Chaffe's theory and can be used in the daily family communication, so it is mature in the family communication field.

\section{CHAPTER Two ANALYSIS OF THE PREDICAMENT OF FAMILY COMMUNICATIONS}

\section{A. Indifferent Attitude}

A Temporary Matter is told from the third-person perspective of Shukumar. The story unfolds largely in memory as each item Shukumar touches triggers a memory to a happier time in the couple's life together. Then, indifferent attitudes between the couple can be easily seen by contrasting past happiness with present suffering. For instance, the birthday candles used during the blackout reminded Shukumar of a surprise party Shoba threw for him. Although they were once a happy immigrant couple and both of them were delighted to talk with each other or share their dreams of marriage, they gradually show indifferent attitudes towards each other without immediate communication after the death of their son. Different from the past, they didn't have passions to realize the dreams, to fulfill their desires and longings. Husband and wife have become strangers. To Shoba, the house could be treated just like a hotel. Even the mess and disharmonious collocation could no longer bother her. During the dinner, they even served themselves without any words. They weren't like this before, but now even Shukumar had to struggle to say something that interested the other. Eventually, he gave up trying to amuse his wife and learned not to mind the silence. The only time in the day Shoba sought Shukumar out was to say, "Don't work too hard." before she headed off to bed. Shukumar had come to dread it, because he knew this greeting was something she forced herself to do, and he didn't want to pretend to be happy. The intimate relationship between Shoba and Shukumar had gone forever. Since they no longer share experiences, the couple gradually grows apart.

\section{B. Tendency to Escape}

Apart from the indifferent attitudes the couple showed towards each other, there are other predicaments, such as the tendency to escape, which make the communication much harder to realize. While we may think of alienation as a precondition of migrant identity, in fact, it is a condition that is familiar to most families [1]. Shoba and Shukumar used to be so thrilled to be married, to be living together in their sweet house at last, and they would just reach for each other foolishly. But now, their relationship cooled down, and they just tried their best to escape from reality and reduce the meeting time. Shoba has always gone to work by the time the husband woke up. The more time Shoba began to put in working or taking on additional projects, the more Shukumar was willing to stay in their three-bedroom house. Gradually, this spouse had become experts at avoiding each other. Shukumar even set up his desk in the room which Shona avoided deliberately. The couple had stopped attending parties, went nowhere together as well. It was alienation that makes the communication disorder emerging. 


\section{ChaPter Three MAIN CAUSES OF COMMUNICATION DISORDERS}

There is nothing ambiguous about the significant influence that communication disorders have on the development of family relationship. This paper concludes the causes of emerging the communication barrier in A Temporary Matter from four aspects, including cultural background, living environment, views of marriage and love, and negative accidents.

\section{A. Cultural Background}

In spite of the same identity of second-generation Indian immigrants, the parts of the couple's cultural identities are really different. Differ from the growing environment of Shoba, the time Shukumar had spent in India was much shorter than that of Shoba. Since the first time he had gone to India as an infant he had nearly died of amoebic dysentery. So his father, a nervous type, was afraid to take him again, in case the alike bad things were to happen, and then left him with his aunt and uncle in Concord when he went back to India. It wasn't until after his father died, in his last year of college that India began to interest Shukumar, and he studied its history from course books. Different from indirect experience which Shukumar had, Shoba spend much time of her childhood in India. Under such a difference, India character has deep influence on Shoba. Meanwhile, Shukumar accepted Americanized education so he has been irrevocably shaped by American culture and his ideas and outlook on life are all American style. The difference in cultural background can cultivate different ways of thinking, which can be the root cause of the communication barrier between the family in A Temporary Matter.

\section{B. Living Environment}

Communication disorders spring from the pressure of life as well. Shukumar was in his sixth year of graduate school at the age of 35 . For better development, he was even attending an academic conference outside their living town when Shoba went into the delivery room. After the death of their child, editor Shoba spends more time at work, leaving before Shukumar wakes and coming home late. Besides, Shukumar had been granted more time to work on his dissertation. Though his adviser had urged him to wrap things up, he finds himself unable to concentrate on his work because of the pressure of family relationship. The stress of life seemed to have deprived Shoba and Shukumar of their passion of life and opportunities of communicating.

\section{Views of Marriage and Love}

Different views of marriage and love result from different cultural backgrounds between this couple. Deeply influenced by American culture, Shukumar paid little attention to the fact that the baby had been born dead. He believed that this would pass, and he and Shoba could get through it all at last. He took it for granted that Shoba was only thirty-three, and was strong and healthy enough to have another baby in the future. Unlike the thoughts of Shukumar, Shoba believed that a family without child is not so much of a family as a body without soul in a man. Even her mother, a religious woman, kept praying twice a day for a healthy grandchildren in the future. The death of their child was a serious hit not only to Shoba, but also to her mother. Generally, different values had a negative influence on the communication between this couple and destabilized this family.

\section{Significant Events}

Significant events are usually direct causes which give rise to the communication disorders in family relationship. In A Temporary Matter, the sorrow of the lost child was that important accident which causes a communication breakdown in the relationship of Shukumar and Shoba directly. Six months earlier, Shoba went into labor prematurely when Shukumar was attending a conference out of town. Shukumar was alerted of the labor complications, but by the time he arrived at the Boston hospital, their child had already died. The fact that Shukumar was even absence when Shoba had a cesarean, without doubt, enhanced the estrangement of their relationship. After the death of baby, sad Shoba could not saw the same feeling in her husband, which made Shoba thought that Shukumar didn't care about her. It's feeling like that only dichotomy of care and neglect accompanies her. She could only give vent to her husband in the form of cold war [4]. Ultimately, it is the baby who will never cry who tears the two apart. This silence between them eventually destroys them because, in their grief, Shukumar and Shoba began to grow distant as time passed.

\section{CHAPTER Four STRATEgIES FOR SOLVING THE PROBLEM}

The importance of communication within a marriage is a prevalent theme in Interpreter of Maladies, and A Temporary Matter as well. Nevertheless, the communication barrier can be avoided or mitigated through several approaches. This thesis puts forward two ways of clearing the barrier as follows.

\section{A. Discuss Issues by Making Face-to-face Conversations}

All the secrets and estrangements need communications to clear, which can be realized through immediate and face-toface conversations. Elsewhere, the truths characters do not know or cannot reconcile have similarly wounding effects on their family relationship. What's more, the cultural difference between the couple should encourage exchange, communication and interaction among different cultures rather than resulting in cultural barrier or even spiritual barrier between the family relationship. The effective communication between the spouse can be realized through suitable opportunities, proper preparations and joint efforts of both sides. In the story, the blackout can be seen as an opportunity for having dinner together to connect. At least, Shukumar and Shoba are able to be intimate in the dark. The couple does seem to have some honest self-disclosure by telling each other something they've never told before during these blackout sessions. Shoba prepared the game to communicate while Shukumar planned for the dinner. During the exchange of confessions, the strained relations between Shoba and Shukumar had been eased apparently, and it is hopeful that their relationship might return to what it used to be. 


\section{B. Listen to and Understand Each Other}

During the talk, listening and understanding are important factors which promote the successful communication as well. Shukumar and Shoba use the blackout as an opportunity to spill all the negative stuff they never bothered to reveal before. Being a good listener is a must during this process. When secrets are revealed, the suffering is exposed as well. At that time, people need to learn to understand each other or just be there for the other. What's more, when there is understanding within a relationship, the suffering and misunderstandings can eventually be cleared and even bitterness might turns to love. Shoba took Shukumar's hands and pressed it, moving closer to him when he is sorrowful. Although their final secrets are painful ones, they can eventually feeling been cared and loved. Only in this way can they surmount the difficulties and settle the communication disorder.

\section{CONCLUSION}

Lahiri's stories do not just contain the malady of secrets between spouses, but also concern about broader social issues [7], such as communication disorders in family relationship. Through the interpretation of A Temporary Matter from the perspective of communication disorders, the main body of this thesis illustrates the predicament of family communications and main causes of communication barriers. The comparison of the living conditions between Shukumar and Shoba shows the indifference and estrangement between them. The loss of child and the lack of companionship and communication during the bereavement are the direct causes of the communication obstacles in this story. The pressure from life is an external reason why the couple alienates their relationship and attempts to abandon their friends. Cultural differences and the resulting differences in values of marriage and love are internal causes. After the analysis of these reasons, this article combines the plot of the novel, puts forward universal advice on the solution of communication disorders from two aspects. One is to make face-to-face conversations to give each other an opportunity to open the heart and discuss the problem directly. Another is to be thoughtful, considerate and patient enough to listen to and understand each other.

During the research, it is found that family atmosphere and the communication pattern will change along with the emergence of communication disorders. It is common that husband and wife may face the silence and remoteness in their relationship after some unforeseen accidents. Even though we can't avoid them, we can change the track and guide them in a positive way. Then, solutions mentioned above might give the spouses a hand to amend the family relationship under these circumstances.

\section{REFERENCES}

[1] Bahri Deepika. Aliens, Aliases, Surrogates and Familiars: The Family in Jhumpa Lahiri's Short Stories [J]. South Asia: Journal of South Asian Studies, 2013,36(1):37-49.

[2] Caeser, Judith. American Space in the Fiction of Jhumpa Lahiri[J].English Studies in Canada,2005, (01):50-68.

[3] Dumlao, Rebecca and Renee A. Botta. Family Communication Patterns and the Conflict Styles Young Adults Use[J]. Communication Quarterly, 2000, 55(01): 174-189.

[4] Jin Renshun. Love and Sorrow: After Reading Jhumpa Lahiri's Novels [J]. Comparative Literature in China,2014,(03):194-203.(In Chinese)

[5] Koerner, Ascan F. and Marry Anne Fitzpatrick. Family Type and Conflict: The Impact of conversation Orientation and Conformity Orientation on conflict in the family $[\mathrm{J}]$. Communication Studies, 2009,48(01):59-75.

[6] Koerner, Ascan F. and Paul Schrodt.An Introduction to the Special Issue on Family Communication Patterns Theory[J].Journal of Family Communication ,2014,14(01):1-15.

[7] Noor Ronny. Reviewed Works: Interpreter of Maladies by Jhumpa Lahiri.[DB/OL] http://www.jstor.org/stable/40155634,2017.

[8] Tyrell Michael. Reviewed Works: Interpreter of Maladies by Jhumpa Lahiri[J]. Harvard Review, Pleasures and pleasures pleasures and pleasur ,1999,(No. 17):198-199.

[9] Xie Yulu. The Anxiety and Pursuit of Identity: Interpretation of the Identity Issues in the Three Popular Indian Female Writers [D]. Sichuan Normal University,2011. (In Chinese)

[10] Zhang Qin. Family Communication Patterns and Conflict Styles in Chinese Relationships [J]. Communication Quarterly,2007,55(01):113128. 